Keywords: elderly; locally advanced non-small-cell lung cancer; concurrent chemoradiotherapy; comprehensive geriatric assessment; decision-making

\title{
Geriatric assessment may help decision- making in elderly patients with inoperable, locally advanced non-small-cell lung cancer
}

Maite Antonio ${ }^{1,2}$, Juana Saldaña ${ }^{1,2}$, Jennifer Linares ${ }^{1}$, José C Ruffinelli ${ }^{1}$, Ramón Palmero ${ }^{1}$, Arturo Navarro ${ }^{3}$, Maria Dolores Arnaiz ${ }^{3}$, Isabel Brao ${ }^{1}$, Samantha Aso ${ }^{4}$, Susana Padrones ${ }^{4}$, Valentí Navarro ${ }^{5}$, Jesús González-Barboteo ${ }^{6}$, Josep Maria Borràs ${ }^{7}$, Felipe Cardenal $^{1}$ and Ernest Nadal ${ }^{\star, 1,8}$

${ }^{1}$ Thoracic Oncology Unit, Department of Medical Oncology, Institut Català d'Oncologia, Hospital Duran i Reynals, Avinguda Gran via 199-203. L'Hospitalet, Barcelona 08908, Spain; ${ }^{2}$ Geriatric Oncology Unit, Department of Medical Oncology, Institut Català d'Oncologia, Avinguda Gran via 199-203. L'Hospitalet, Barcelona 08908, Spain; ${ }^{3}$ Thoracic Oncology Unit, Department of Radiation Oncology, Institut Català d'Oncologia. Avinguda Gran via 199-203. L'Hospitalet, Barcelona 08908, Spain; ${ }^{4}$ Department of Respiratory Medicine, Hospital Universitari de Bellvitge, Feixa Llarga, s/n, 08907. L'Hospitalet, Barcelona 08907, Spain; ${ }^{5} \mathrm{Clinical}$ Research Unit, Institut Català d'Oncologia, Avinguda Gran via 199-203. L'Hospitalet, Barcelona 08908, Spain; ${ }^{6}$ Palliative Care Unit, Institut Català d'Oncologia, Avinguda Gran via 199-203. L'Hospitalet, Barcelona 08908, Spain; ${ }^{7}$ Department of Clinical Sciences, IDIBELL, University of Barcelona, Feixa Llarga, s/n, 08908. L'Hospitalet, Barcelona 08907, Spain and ${ }^{8}$ Clinical Research in Solid Tumors (CReST) Group, OncoBell Program, IDIBELL, Avinguda Gran via 199-203. L'Hospitalet, Barcelona 08908, Spain

Background: Although concurrent chemoradiotherapy (CCRT) increases survival in patients with inoperable, locally advanced nonsmall-cell lung cancer (NSCLC), there is no consensus on the treatment of elderly patients. The aim of this study was to determine the prognostic value of the comprehensive geriatric assessment (CGA) and its ability to predict toxicity in this setting.

Methods: We enrolled 85 consecutive elderly ( $\geqslant 75$ years) participants, who underwent CGA and the Vulnerable Elders Survey (VES-13). Those classified as fit and medium-fit by CGA were deemed candidates for cCRT (platinum-based chemotherapy concurrent with thoracic radiation therapy), while unfit patients received best supportive care.

Results: Fit (37\%) and medium-fit (48\%) patients had significantly longer median overall survival (mOS) (23.9 and 16.9 months, respectively) than unfit patients (15\%) $(9.3$ months, log-rank $P=0.01)$. In multivariate analysis, CGA groups and VES-13 were independent prognostic factors. Fit and medium-fit patients receiving cCRT $(n=54)$ had mOS of 21.1 months $(95 \%$ confidence interval: 16.2, 26.0). In those patients, higher VES-13 ( $\geqslant 3$ ) was associated with shorter mOS (16.33 vs 24.3 months, $P=0.027)$ and higher risk of G3-4 toxicity (65 vs 32\%, $P=0.028$ ).

Conclusions: Comprehensive geriatric assessment and VES-13 showed independent prognostic value. Comprehensive geriatric assessment may help to identify elderly patients fit enough to be treated with cCRT.

As a result of population ageing and increasing incidence of lung cancer in the elderly, oncologists commonly face the challenge of effectively managing older adults with lung cancer (Wingo et al,
2003). Non-small-cell lung cancer (NSCLC) accounts for more than $80 \%$ of all lung cancers, and $25-30 \%$ of NSCLC patients are diagnosed with locally advanced disease (Walters et al, 2013).

*Correspondence: E Nadal; E-mail: esnadal@iconcologia.net

Received 3 July 2017; revised 18 November 2017; accepted 22 November 2017; published online 30 January 2018

(C) 2018 Cancer Research UK. All rights reserved 0007-0920/18 
Concurrent chemoradiotherapy (cCRT) is the standard treatment for good performance status patients with inoperable locally advanced NSCLC (Furuse et al, 1995; Aupérin et al, 2010; O’Rourke et al, 2010; Ramnath et al, 2013; Bezjak et al, 2015; Eberhardt et al, 2015). Chemoradiotherapy is considered a reasonable standard of care for fit elderly patients (Pallis et al, 2014; Dawe et al, 2016). However, as a result of misperceptions about poorer survival and higher risk of toxicity, oncologists are often reluctant to treat older patients using conventional therapy at standard doses (Schild et al, 2007; Cardenal et al, 2015). In addition, it remains unclear whether cCRT is suitable for unselected elderly patients due to the limited data available from clinical trials (Werner-Wasik et al, 2000; Rocha Lima et al, 2002; Firat et al, 2006; Schild et al, 2007; Davidoff et al, 2011; Pang et al, 2016). Consequently, undertreatment and overtreatment bias in older adults with inoperable locally advanced NSCLC is a concern.

Ageing is characterised by great heterogeneity, so advanced age alone should not prevent people from accessing the most appropriate treatment (Hung and Mullins, 2013). In all patients, treating physicians have to balance the risk of death due to lung cancer against the potential survival benefit of treatment, but in the elderly they should pay particular attention to the risk of treatment-related adverse events and the patient's life expectancy irrespective of cancer (Pallis et al, 2014; Antonio et al, 2017). Comprehensive geriatric assessment (CGA) is considered the gold standard for characterising elderly patients according to their frailty profile (Balducci and Beghe, 2000a; Solomon et al, 2003; Extermann et al, 2005; Handforth et al, 2014). Comprehensive geriatric assessment is a multidimensional tool based on several scales that estimates physiological reserves and helps predict poor treatment outcomes, including toxicity, morbidity, and mortality (Extermann and Hurria, 2007). Comprehensive geriatric assessment includes assessment with standardised tools, an intervention plan and follow-through. Because CGA is time consuming and requires expertise to interpret the results and implement the appropriate interventions, screening tools like the Vulnerable Elders Survey (VES-13) are used to preselect the fittest patients from the rest of the elderly population for whom a full CGA might be indicated (Decoster et al, 2015).

The main objective of this prospective pilot study is to examine the prognostic value of CGA and its ability to predict toxicity in elderly patients with inoperable, locally advanced NSCLC. A secondary objective was to explore the clinical value of the VES-13 in this clinical setting.

\section{MATERIALS AND METHODS}

Study design and participants. This prospective study was conducted at the Institut Català d'Oncologia in L'Hospitalet de Llobregat, Barcelona. Since 2008 all newly diagnosed lung cancer patients aged 75 years or older who are deemed candidates for chemotherapy (with or without radiotherapy) have been systematically referred to the Geriatric Oncology Unit to undergo CGA. Eligible patients for this study were aged 75 years or older, had histological or cytological confirmation of locally advanced NSCLC based on clinical assessments (cardiopulmonary function, contrast thoracic computed tomography (CT) and positron-emitted tomography-CT (PET-CT) scan, and selective mediastinal staging with endobronchial ultrasonography and/or oesophageal ultrasonography), and were considered candidates for nonsurgical cancer treatment by the Multidisciplinary Thoracic Oncology Tumour Board. We prospectively collected the following data: age, sex, smoking history, Eastern Cooperative Oncology Group (ECOG) performance status, histology, and clinical stage according to the 7 th edition of TNM, regimen of chemotherapy and radiotherapy, treatment-related toxicity, CGA variables, and VES-13 scores.

All data related to patients, tumour characteristics, and CGA results were recorded anonymously by the study investigators at the Geriatric Oncology Unit. As the study was based on current clinical practice, all patients signed the standard informed consent form for receiving cCRT. The Institutional Review Board approved the study.

Geriatric assessment. A team including a geriatrician and a geriatric oncologist assessed all patients by means of a CGA that incorporated validated instruments to explore eight domains: functional status, nutritional status, cognitive status, psychological status, comorbidities, medication, social support, and geriatric syndromes (Supplementary Table S1). Functional status was measured using two instruments: (a) the Barthel Activities of Daily Living (ADL) (Mahoney and Barthel, 1965), which uses a 0-100 scale to assess 10 basic self-care abilities (e.g., transfer, bathing, toileting, dressing, feeding); and (b) the Lawton Index of Instrumental Activities of Daily Living (IADL) (Lawton and Brody, 1969), an instrument assessing individuals' ability to independently interact with the external environment in eight complex daily activities: shopping, cooking, using the telephone, handling finances, housekeeping, laundry, self-managing medication, and using transportation; the summary score ranges from 0 (low function, dependent) to 8 (high function, independent). To assess nutritional status, participants were asked if they had unintentionally lost over $5 \%$ of their body weight in the previous 3 months. The team assessed cognitive status using the Short Portable Mental Status Questionnaire (Pfeiffer's test), which assigns a score from 0 to 10 based on the number of incorrect answers (Pfeiffer, 1975); mood was examined using the four-item Mini-Geriatric Depression Scale (D'Ath et al, 1994); and comorbidity using the Cumulative Illness Rating Scale for Geriatrics, with relevant comorbid conditions defined as those scoring three or more (Linn et al, 1968). We collected data on current medication according to self-report and the participants' medical charts, defining polypharmacy as taking five or more oral medications each day. We considered that participants had a good social environment if they had a primary caregiver, support at home, or a strong circle of friends and family capable of meeting the patient's needs. We determined the presence of a geriatric syndrome by selfreported number of falls in the previous 6 months, cognitive impairment, delirium, and urinary and/or faecal incontinence. If Pfeiffer's test indicated cognitive impairment, we referred the participant to a neuropsychologist for further assessment, classifying significant cognitive impairment as a geriatric syndrome rather than a comorbid condition to avoid overlap between comorbidity and geriatric syndrome domains. We considered only incontinence other than stress incontinence to be a geriatric syndrome.

Using the modification of the CGA proposed by Balducci and Beghe (2000b), we classified participants as 'fit', 'medium-fit', and 'unfit' (Supplementary Table S2). We defined fit as being able to independently perform all ADLs and IADLs, having no more than one clinically significant comorbid condition, and not having any geriatric syndromes. Medium-fit participants could have up to two clinically significant comorbid conditions and up to three IADL impairments, but no ADL disabilities or geriatric syndromes. Unfit participants were those with any ADL disability, more than three IADL disabilities, more than two clinically significant comorbidities, or any geriatric syndrome.

In addition to CGA, we incorporated the Vulnerable Elders Survey (VES-13), a vulnerability screening tool consisting of four groups of questions related to age, self-perceived health, difficulties to perform six specific activities, and difficulties to perform daily living tasks (Saliba et al, 2001). Vulnerability was defined as a VES13 score of 3 or more on a $0-9$ scale. 
Treatment and follow-up. Treatment plan was based on CGA classification, and patients considered fit or medium-fit based on CGA were deemed candidates for cCRT. Radiotherapy was administered concurrently from the first day of chemotherapy up to a total dose of 60-66 Gy in daily fractions of 2 Gy over 6 weeks using a $3 \mathrm{D}$ technique. A specific CT scan of the thorax was performed using intravenous contrast. A PET-CT scan was used to contour the gross tumour volume (GTV). Only lymph node areas with suspicious uptake, pathological CT findings, or pathological confirmation of malignancy were included in the GTV (selective nodal irradiation) following international recommendations (De Ruysscher et al, 2010; Ramnath et al, 2013). No prophylactic nodal irradiation was performed. Organs at risk, such as the lungs, trachea, spinal cord, and oesophagus were contoured as per international guidelines (Kong et al, 2011). The following dose constraints were applied: for the lungs, $V_{20}$ (volume of the healthy lung receiving $<20 \mathrm{~Gy}$ ) lower than 35\%; for the oesophagus, mean dose of $<34 \mathrm{~Gy}$; and for the spinal cord, mean dose of $<45 \mathrm{~Gy}$. None of the patients received intensity-modulated radiation therapy. The mean GTV for patients treated with thoracic radiotherapy was $149.23 \mathrm{~cm}^{3}$.

The treating physician used distinct platinum-based chemotherapy regimens (Supplementary Table S3), none of which included consolidation chemotherapy. Fit and medium-fit patients not undergoing CCRT for any reason were followed up. None of the participants classified as unfit received any active therapy and were assigned to best supportive care and followed up.

Statistical analysis. We expressed patient characteristics and geriatric variables as percentages for qualitative variables and as mean and standard deviation (s.d.) for quantitative variables. Toxicity was scored according to the National Cancer InstituteCommon Toxicity Criteria for Adverse Events version 4.0 before each cycle. We recorded data on treatment adherence and cause of discontinuation for any reason. Overall survival (OS) was defined as the time from pathological diagnosis until the date of death due to any cause or the last date the patient was known to be alive.
Survival curves were plotted using the Kaplan-Meier method, and differences were assessed using the log-rank test. We constructed univariate and multivariate Cox proportional hazards models and analysed data using SPSS Statistics for Windows, version 17.0 (SPSS Inc., Chicago, IL, USA).

\section{RESULTS}

Participant characteristics and geriatric assessment. From July 2008 to September 2016, 85 elderly patients with inoperable, locally advanced NSCLC were enrolled in the study. Mean follow-up was 24 months. Most patients (89\%) were men and had a history of smoking (91\%). Median age was 79.5 years (range $75-87$ ), and a significant subset of participants (51\%) was 80 years or older. The most common histological subtype was squamous cell carcinoma (55\%), followed by adenocarcinoma (24\%); a further $21 \%$ had an unspecified subtype $(21 \%)$. Most patients $(n=66,78 \%)$ had good ECOG performance status $(<2)$ at study entry.

Based on CGA, 31 (37\%) participants were classified as fit, 41 $(48 \%)$ as medium-fit, and $13(15 \%)$ as unfit. A flowchart is presented in Figure 1. There were no statistically significant differences between these groups with regard to age, sex, smoking history, histology, or tumour stage (Table 1). Performance status was significantly correlated with CGA groups $(P<0.001)$, with poorer scores $(\geqslant 2)$ more common in medium-fit $(19.5 \%)$ and unfit patients (77\%) compared with fit patients (3\%). We also observed a significant correlation between CGA groups and VES13 scale $(P<0.001)$. Interestingly, the VES-13 scale classified $23 \%$ of fit and $68 \%$ of medium-fit patients as vulnerable ( $\geqslant 3$ score).

Univariate and multivariate analysis of OS. At the data cutoff point for this survival analysis, 65 out of 85 patients had died. At mean follow-up of 24 months, median OS was 17.7 months (95\% confidence interval (CI): 14.9, 20.6). Regardless of the treatment received, the CGA categories were significantly associated with OS.

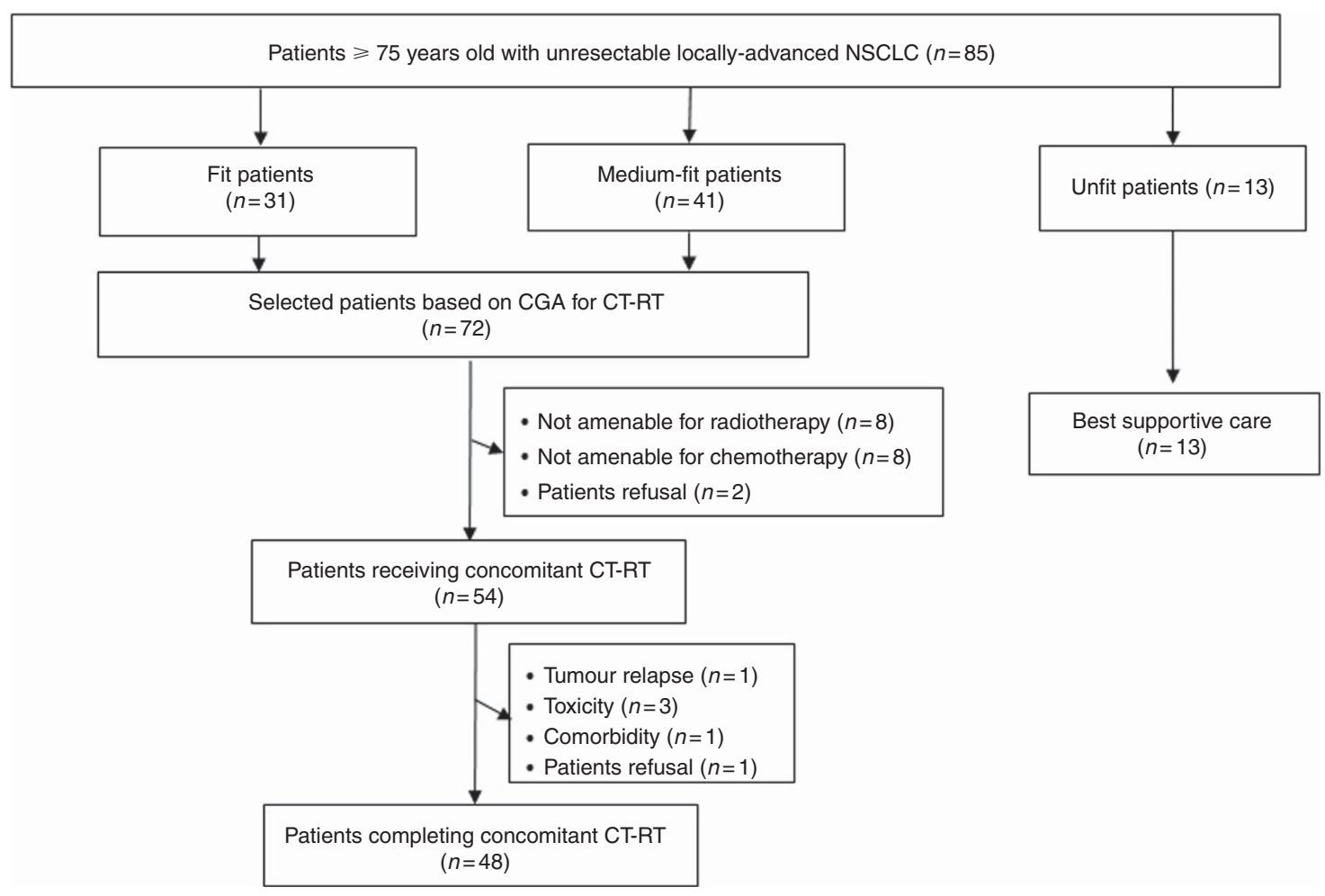

Figure 1. Study flowchart. CGA=comprehensive geriatric assessment; NSCLC=non-small-cell lung cancer. 
Table 1. Clinicopathological characteristics and geriatric features according to the CGA risk groups

\begin{tabular}{|c|c|c|c|c|c|}
\hline & Fit, $n=31$ & Medium-fit, $n=41$ & Unfit, $n=13$ & All, $n=85$ & $P$-value \\
\hline $\begin{array}{l}\text { Age (years) } \\
\quad \text { Median } \\
\geqslant 80, n(\%)\end{array}$ & $\begin{array}{c}79.7 \\
17(55)\end{array}$ & $\begin{array}{c}79.0 \\
18(45)\end{array}$ & $\begin{array}{c}80.5 \\
8(61.5)\end{array}$ & $\begin{array}{c}79.5 \\
43(51)\end{array}$ & $\begin{array}{l}0.290^{a} \\
0.454^{b}\end{array}$ \\
\hline $\begin{array}{l}\text { Sex, } n(\%) \\
\text { Men } \\
\text { Women }\end{array}$ & $\begin{array}{c}26(84) \\
5(16)\end{array}$ & $\begin{array}{c}39(95) \\
2(5)\end{array}$ & $\begin{array}{l}11(85) \\
2(15)\end{array}$ & $\begin{array}{c}76(89) \\
9(11)\end{array}$ & $0.255^{\mathrm{b}}$ \\
\hline $\begin{array}{l}\text { Smoking history, } n \text { ( } \\
\text { Current } \\
\text { Former } \\
\text { Never }\end{array}$ & $\begin{array}{c}4(13) \\
22(71) \\
5(16)\end{array}$ & $\begin{array}{c}9(22) \\
30(73) \\
2(5)\end{array}$ & $\begin{array}{c}3(23) \\
9(69) \\
1(8)\end{array}$ & $\begin{array}{c}16(19) \\
61(72) \\
8(9)\end{array}$ & $0.499^{b}$ \\
\hline $\begin{array}{l}\text { Histology, n (\%) } \\
\text { Squamous cell } \\
\text { Adenocarcinoma } \\
\text { Unspecified }\end{array}$ & $\begin{array}{c}11(35.5) \\
11(35.5) \\
9(29)\end{array}$ & $\begin{array}{c}26(63.5) \\
7(17) \\
8(19.5)\end{array}$ & $\begin{array}{c}10(77) \\
2(15) \\
1(8)\end{array}$ & $\begin{array}{l}47(55) \\
20(24) \\
18(21)\end{array}$ & $0.065^{b}$ \\
\hline $\begin{array}{l}\text { Stage, } n(\%) \\
\text { ॥A } \\
\text { ॥B } \\
\text { IIA } \\
\text { ॥B }\end{array}$ & $\begin{array}{c}1(3) \\
3(10) \\
20(64) \\
7(23)\end{array}$ & $\begin{array}{c}2(5) \\
4(10) \\
23(56) \\
12(29)\end{array}$ & $\begin{array}{l}0(0) \\
1(8) \\
6(46) \\
6(46)\end{array}$ & $\begin{array}{c}3(4) \\
8(9) \\
48(58) \\
25(29)\end{array}$ & $0.806^{b}$ \\
\hline $\begin{array}{l}\text { ECOG-PS, n (\%) } \\
\quad 0-1 \\
\geqslant 2\end{array}$ & $\begin{array}{c}30(97) \\
1(3)\end{array}$ & $\begin{array}{c}33(80.5) \\
8(19.5)\end{array}$ & $\begin{array}{c}3(23) \\
10(77)\end{array}$ & $\begin{array}{l}66(78) \\
19(22)\end{array}$ & $<0.001^{b}$ \\
\hline
\end{tabular}

\section{Geriatric assessment variables}

Physical function, $n$ (\%)

ADL - Barthel

$\geqslant 90$

$<90$

IADL - Lawton

$\geqslant 5$

$<5$

Cognitive function, $n(\%)$

Pfeiffer

$<2$

$\geqslant 2$

Mood assessment, $n$ (\%)

Yesavage

$<1$

$\geqslant 1$

Comorbidity, $n$ (\%)

CIRS-G

Total score (median) Severity score (median)

Polypharmacy, n (\%)

$\leqslant 5$

$>5$

Geriatric syndromes, $n(\%)$

0

$\geqslant 1$

Social support, $n(\%)$

Yes

No

Weight loss, $n$ (\%)

$<5 \%$

$>5 \%$

VES-13 scale, $n$ (\%)

$<3$

$\geqslant 3$

1 (3)

$8(19.5)$

$10(77)$

19 (22)

$<0.001^{\mathrm{b}}$

Abbreviations: $A D L=$ Barthel Activities of Daily Living; $A N O V A=$ analysis of variance; $C G A=$ comprehensive geriatric assessment; CIRS-G =Cumulative IInness Ratio Scale for Geriatrics; ECOG-PS = Eastern Cooperative Oncology Group performance status; IADL= Lawton Index of Instrumental Activities of Daily Living; VES-13=Vulnerable Elders Survey. Values in bold are statistically significant.

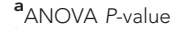

$\mathbf{b}_{\chi^{2}} P$-value. 
A

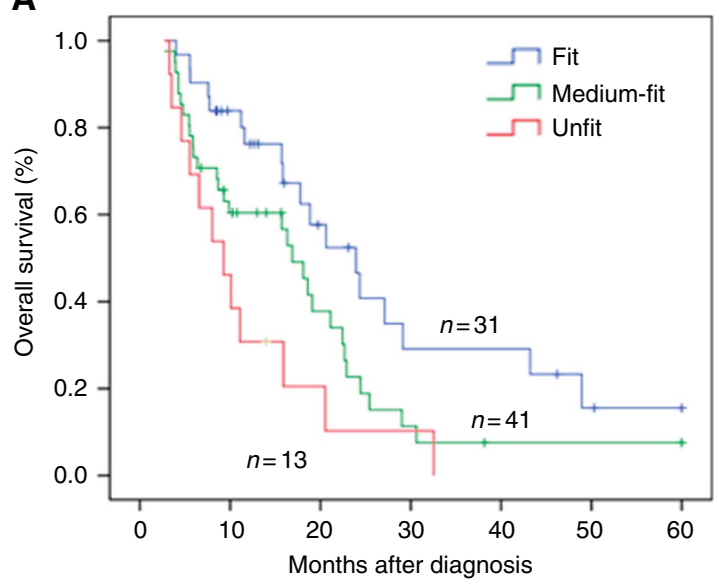

C

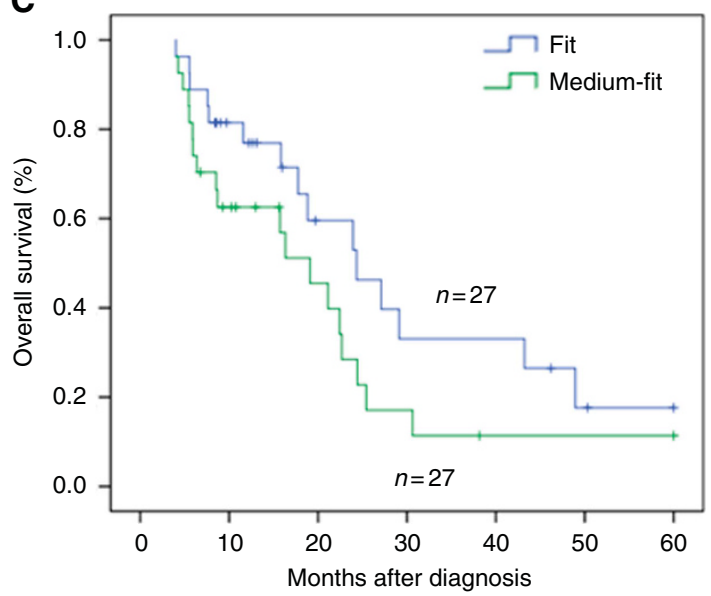

B
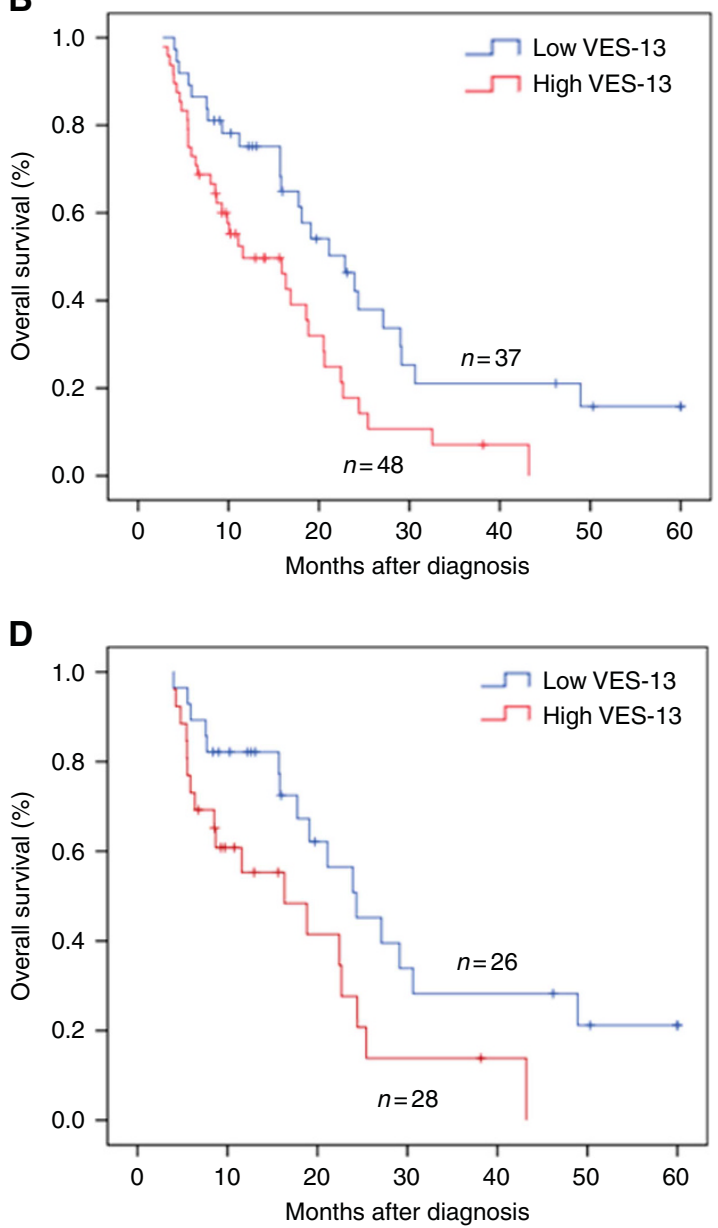

Figure 2. Kaplan-Meier plots of OS that include the whole cohort of patients ( $n=85$ ) classified according to CGA (A) and VES-13 (B), and the subset of patients treated with chemoradiotherapy $(n=54)$ classified by CGA (C) and VES-13 (D). CGA = comprehensive geriatric assessment; OS $=$ overall survival; VES-13 = Vulnerable Elders Survey.

Table 2. Multivariate Cox regression analysis of OS for all patients $(n=85)$ based on CGA and VES-13 categories

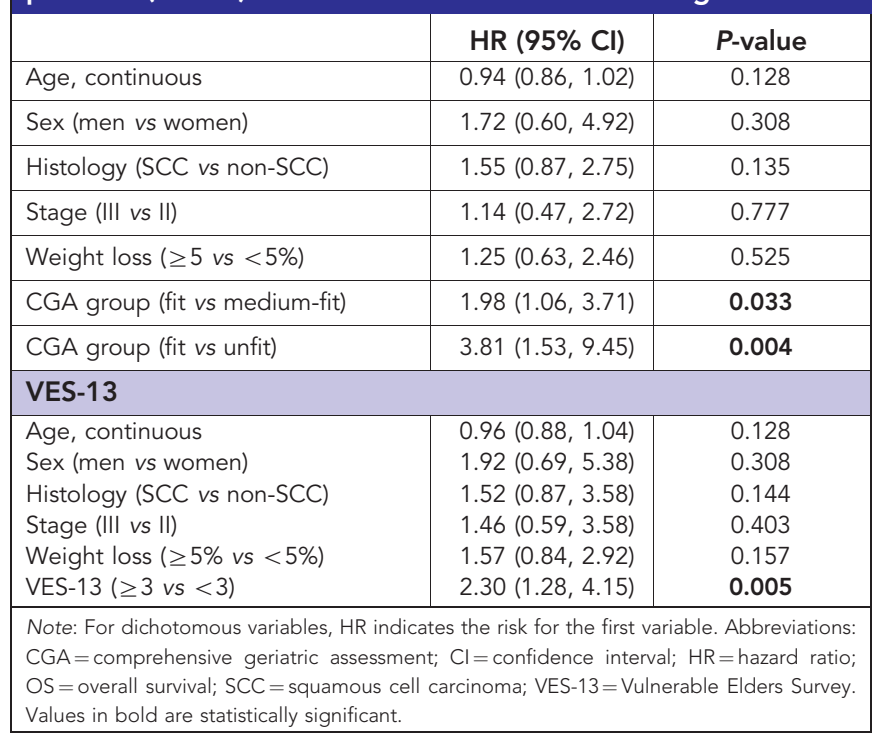

Median OS was significantly shorter for unfit and medium-fit patients (9.3 and 16.9 months, respectively) compared with fit patients (23.9 months, log-rank $P=0.01$; Figure 2A). The respective 2- and 5-year OS rates were $47 \%$ and $15 \%$ in fit, $23 \%$ and $8 \%$ in medium-fit, and $10 \%$ and $0 \%$ in unfit participants.

Participants with a VES-13 score indicating vulnerability $(\geqslant 3)$ also had significantly shorter median OS (11.6 months, 95\% CI: $4.3,18.9)$ than non-vulnerable patients (22.9 months, $95 \%$ CI: 16.1 , 29.6; $\log$-rank $P=0.007$; Figure $2 \mathrm{~B}$ ).

In the univariate Cox regression analysis, performance status, geriatric classification, and VES-13 were prognostic factors for OS (Supplementary Table S4). In the multivariate Cox regression analysis adjusted for age, sex, histology, tumour stage, and weight loss, and compared to fit participants, OS was worse for mediumfit (hazard ratio (HR) 1.98, 95\% CI: 1.06, 3.71) and unfit groups $(\mathrm{HR}=3.81,95 \% \mathrm{CI}: 1.53,9.45$, Table 2$)$. In the multivariate Cox regression adjusted for the same covariates, vulnerability was also significantly associated with worse $\mathrm{OS}(\mathrm{HR}=2.30,95 \% \mathrm{CI}: 1.28$, 4.15, $P=0.005$, Table 2).

Survival results in patients treated with cCRT. All patients classified as unfit $(n=13)$ received best supportive care, which included palliative thoracic radiotherapy in four cases. Out of 72 fit and medium-fit patients initially considered candidates for cCRT, only 54 patients (75\%) were actually treated (Figure 1). The reasons for not administering cCRT were: non-suitable for radiotherapy (tumour extension or poor respiratory function) $(n=8)$, specific contraindication to chemotherapy $(n=8)$, and patient's decision $(n=2)$.

Patients treated with cCRT $(n=54)$ achieved a median OS of 21.1 months (95\% CI: 16.2, 26.0). Most participants (89\%) 
Table 3. Moderate and severe toxicity in patients treated with concurrent chemoradiotherapy according to the CGA groups $(n=54)$

\begin{tabular}{|c|c|c|c|c|c|c|}
\hline \multirow[b]{2}{*}{ Toxicity } & \multicolumn{2}{|c|}{ Fit $(n=27)$} & \multicolumn{2}{|c|}{$\begin{array}{l}\text { Medium-fit } \\
\quad(n=27)\end{array}$} & \multicolumn{2}{|c|}{ Total $(n=54)$} \\
\hline & $\begin{array}{c}\text { G3-4, } \\
\text { n (\%) }\end{array}$ & $\begin{array}{c}\text { G5, } \\
\text { n (\%) }\end{array}$ & $\begin{array}{l}\text { G3-4, } \\
n(\%)\end{array}$ & \begin{tabular}{|c|} 
G5, \\
n (\%)
\end{tabular} & $\begin{array}{l}\text { G3-4, } \\
\text { n (\%) }\end{array}$ & $\begin{array}{c}\text { G5, } \\
\text { n (\%) }\end{array}$ \\
\hline Neutropenia & $7(26)$ & $0(0)$ & $4(15)$ & $0(0)$ & $11(20)$ & $0(0)$ \\
\hline $\begin{array}{l}\text { Febrile } \\
\text { neutropenia }\end{array}$ & $2(7.5)$ & $0(0)$ & $2(7.5)$ & $0(0)$ & $4(7.5)$ & $0(0)$ \\
\hline Anaemia & $0(0)$ & $0(0)$ & $2(7.5)$ & $0(0)$ & $2(4)$ & $0(0)$ \\
\hline Thrombocytopenia & $1(4)$ & $0(0)$ & $2(7.5)$ & $0(0)$ & $3(6)$ & $0(0)$ \\
\hline Fatigue & $2(7.5)$ & $0(0)$ & $4(15)$ & $0(0)$ & $6(11)$ & $0(0)$ \\
\hline Diarrhoea & 1 (4) & $0(0)$ & $0(0)$ & $0(0)$ & $1(2)$ & $0(0)$ \\
\hline Oesophagitis & $0(0)$ & $0(0)$ & $1(2)$ & $0(0)$ & $1(2)$ & $0(0)$ \\
\hline $\begin{array}{l}\text { Respiratory } \\
\text { infection }\end{array}$ & $2(7.5)$ & $0(0)$ & $7(26)$ & $2(7.5)$ & 7 (13) & $2(7.5)$ \\
\hline $\begin{array}{l}\text { Radiation } \\
\text { pneumonitis }\end{array}$ & $2(7.5)$ & $0(0)$ & $5(18.5)$ & $2(7.5)$ & 7 (13) & $2(7.5)$ \\
\hline
\end{tabular}

completed the planned treatment, and there were no differences in compliance between CGA groups. The reasons for not completing the planned cCRT were treatment-related toxicity $(n=3)$, cancer progression $(n=1)$, patient's decision $(n=1)$, or aggravation of comorbidities $(n=1)$.

The chemotherapy schedules used most often were carboplatin 2.5 AUCs (area under the plasma drug concentration-time curve) plus vinorelbine $15 \mathrm{mg} \mathrm{m}^{-2}$ on days $1,8,22$, and 29 and weekly carboplatin 2 AUCs plus paclitaxel $45 \mathrm{mg} \mathrm{m}^{-2}$ (Supplementary Table S3).

Analysis did not show any statistically significant differences in median OS between fit and medium-fit patients treated with cCRT (24.3 and 19.1 months, respectively, log-rank $P=0.096$; Figure 2C). Non-vulnerable patients (according to VES-13) receiving cCRT had significantly longer median OS (24.3 months, $95 \%$ CI: $16.6,32.1)$ than vulnerable patients ( 16.3 months, $95 \% \mathrm{CI}$ : 4.7, 27.9, log-rank $P=0.027$; Figure 2D). Interestingly, in the multivariate Cox regression adjusted for age, sex, histology, tumour stage, and weight loss, vulnerable patients (VES-13 score $\geqslant 3$ ) had significantly shorter median OS (HR 2.90, 95\% CI: 1.30, 6.45, $P=0.009$ ).

Association between CGA and toxicity. Among the 54 patients receiving CCRT, medium-fit patients experienced a higher rate of grade $3-4$ adverse events (59\%) than fit patients (37\%), but these differences were not statistically significant $(P=0.173)$. Vulnerable patients as defined by VES-13 had a significantly higher rate of grade $3-4$ adverse events (65\%) than non-vulnerable patients $(32 \%$, $P=0.028)$. We did not observe differences in grade $3-4$ haematologic toxicity between fit and medium-fit patients or between vulnerable and non-vulnerable patients. Four (3.8\%) fit and no medium-fit patients experienced grade 3-4 haematologic toxicity $(P=0.31)$, while eight $(24 \%)$ fit and three $(10 \%)$ mediumfit patients experienced grade 3-4 non-haematologic toxicity $(P=0.09)$.

The most common grade 3-4 adverse events were neutropenia (20\%), febrile neutropenia (7.5\%), asthaenia/fatigue (11\%), respiratory infection (13\%), and radiation pneumonitis (13\%). All treatment-related deaths occurred in the medium-fit group: two due to radiation pneumonitis and two due to respiratory infection. Toxicity according to geriatric group is summarised in Table 3.

\begin{tabular}{|c|c|c|}
\hline Variable & OR $(95 \% \mathrm{Cl})$ & $P$-value \\
\hline Age, continuous & $0.92(0.76,1.12)$ & 0.409 \\
\hline Sex (men vs women) & $4.35(0.45,41.8)$ & 0.203 \\
\hline Histology (SCC vs non-SCC) & $1.08(0.37,3.19)$ & 0.884 \\
\hline Smoking status (smoker vs never smoker) & $4.35(0.45,41.8)$ & 0.203 \\
\hline Stage (III vs II) & $1.90(0.41,8.94)$ & 0.414 \\
\hline Weight loss ( $\geq 5$ vs $<5 \%$ ) & $1.33(0.27,6.63)$ & 0.725 \\
\hline ECOG-PS ( $\geq 2$ vs $<2)$ & $1.04(0.14,7.99)$ & 0.969 \\
\hline VES-13 score $(\geq 3$ vs $<3)$ & $3.99(1.28,12.37)$ & 0.017 \\
\hline CGA group (medium-fit vs fit) & $2.72(0.89,8.26)$ & 0.078 \\
\hline \multicolumn{3}{|c|}{$\begin{array}{l}\text { Note: For dichotomous variables, the } \mathrm{OR} \text { indicates the risk for the first variable } \\
\text { Abbreviations: } \mathrm{CGA}=\text { comprehensive geriatric assessment; } \mathrm{Cl}=\text { confidence interval } \\
\text { ECOG-PS=Eastern Cooperative Oncology Group performance status; OR=odds ratio } \\
\mathrm{SCC}=\text { squamous cell carcinoma; VES- } 13=\text { Vulnerable Elders Survey. Values in bold are } \\
\text { statistically significant. }\end{array}$} \\
\hline
\end{tabular}

Logistic regression was performed to assess the ability of distinct variables to predict grade 3-4 toxicity. While CGA-defined groups were not predictive of this outcome, vulnerable patients as defined by VES-13 were at significantly higher risk of grade 3-4 toxicity (odds ratio (OR) 3.99, 95\% CI: 1.28, 12.37, $P=0.017$; Table 4).

\section{DISCUSSION}

This prospective study, carried out in the clinical practice setting, included a cohort of 85 consecutive participants aged 75 years or older with inoperable, locally advanced NSCLC who were evaluated by CGA. To our knowledge, this is the first prospective study assessing the value of CGA for selecting patients for cCRT therapy in this specific elderly population, for whom treatment decisions are particularly challenging. Indeed, a significant proportion of participants were octogenarians.

At present, treatment decisions are based on clinical assessment, age, and performance status. Patients of advanced age, with poor performance status, weight loss, or comorbidities are considered 'poor-risk' patients and have generally been excluded from clinical trials evaluating cCRT (Cardenal et al, 2015). However, CGA detects geriatric impairments even in patients with good performance status (Jolly et al, 2015). A recent systematic review on CGA for lung cancer patients found that CGA could detect multiple geriatric impairments that are generally missed by other measures such as ECOG performance status (Schulkes et al, 2016), and some of these can be reversed through subsequent geriatricbased interventions (Kalsi et al, 2015). In our study, 3\% of fit and $19.5 \%$ of medium-fit patients had a performance status score of 2 or more and would be considered as 'poor-risk' and excluded from cCRT.

Most previous studies addressing the relevance of CGA in lung cancer were conducted in patients with advanced disease or with distinct tumour stages (Maione et al, 2005; Corre et al, 2016; Gajra et al, 2016; Karampeazis et al, 2017). Recently, the Elderly Selection on Geriatric Index Assessment study compared a standard strategy of treatment allocation (carboplatin-based doublet or single agent on the basis of performance status and age) $v s$ an experimental CGA-based allocation to the same chemotherapies or best supportive care in elderly patients with advanced NSCLC (Corre et al, 2016). Although that study failed to show an improvement in failure-free survival and OS in patients in the CGA-guided arm, these patients showed better tolerance to chemotherapy and lower 
treatment failure due to toxicity, and nearly one-quarter of them were spared chemotherapy without compromising survival for the whole group.

A recent individual patient data meta-analysis of 16 trials $(n=3600)$ assessing cCRT in unresectable stage III NSCLC included $832(23 \%)$ elderly participants ( $\geqslant 70$ years old); elderly patients had a shorter OS than their younger counterparts (17.0 vs 20.7 months, $P<0.01$ ) (Stinchcombe et al, 2017). The JCOG0301 randomised phase III clinical trial, performed specifically in patients aged 70 years or older with stage III NSCLC, showed better outcomes for cCRT $v s$ RT alone in a group of participants who had not undergone geriatric characterisation (Atagi et al, 2012). An ongoing phase II study assessing CGA in the inoperable, locally advanced NSCLC setting (RACCOSSA, GFPC 08-06) is evaluating tolerance to cCRT (cisplatin plus vinorelbine concurrently with thoracic radiotherapy) in participants aged 70 years or older and considered fit by geriatric assessment (Locher et al, 2011).

We observed a significant association between CGA groups and clinical outcome, as fit and medium-fit patients had longer median OS than unfit patients. This survival outcome cannot be entirely attributed to the expected beneficial effect of cCRT; rather, this difference is likely related to the poorer health profile of unfit patients compared with fit and medium-fit patients. Besides, as our study is non-comparative, the interaction between treatment and CGA categories in terms of prognosis cannot be assessed.

On the other hand, the survival results in the selected group of fit and medium-fit patients who did receive cCRT (median OS 21.1 months, 95\% CI: 16.2, 26.0) were in the range of those reported for younger patients in clinical trials (Santana-Davila et al, 2015; Steuer et al, 2016). Atagi et al (2012) reported that cCRT resulted in a median OS slightly higher than ours (22.4 months, 95\% CI: 16.5, 33.6), but inclusion was restricted to participants of Asian ethnicity with good performance status (96\% of patients had an ECOG score of $0-1$ ). A recent systematic review of sequential or concurrent CRT vs radiotherapy alone in elderly patients with stage III NSCLC concluded that fit patients showed good tolerance to cCRT, which was associated with a $34 \%$ reduction in the hazard ratio for death (Dawe et al, 2016).

Toxicity is a special concern in elderly patients because of its greater potential impact on functionality and quality of life compared to the general population. Our safety data provides support for using cCRT in older adults. In our sample, the rate of grade 3-4 toxicities associated with cCRT was consistent with the range of values reported in other elderly specific studies (Atagi et al, 2012; Dawe et al, 2016). The proportion of participants completing the planned treatment in our selected sample was $78 \%$, and although we do not have a benchmark for this parameter in routine clinical practice, it is higher than that reported by Stinchcombe et al (2017) in elderly patients participating in phase II-III trials (47\%).

Comprehensive geriatric assessment has not been universally adopted as a standard of care because it is time-consuming and resource-intensive for busy oncological practices (Decoster et al, 2015). VES-13 requires less time and professional intervention, and can also be self-administered. The capability of the VES-13 screening tool for predicting prognosis and toxicity in this clinical setting is a remarkable finding of our research. In our study, vulnerable participants (VES-13 $\geqslant 3$ ) had significantly shorter median OS and a higher risk of grade 3-4 toxicity, as previously reported in patients older than 75 years with several tumours (Luciani et al, 2015). The ability of the VES-13 scale to capture physical functioning might explain its capacity to detect vulnerability in lung cancer patients for whom functional status has a significant weight. Although screening tools appear to simplify the geriatric assessment, they skip processes covered by CGA that are relevant for decision-making, such as diagnosing impairments, defining patient priorities, setting the pretreatment baseline, and implementing interventions (Hamaker et al, 2017). For this reason these tools cannot replace CGA (Decoster et al, 2015).

Major strengths of our study are its prospective design; the performance of a standardised CGA on all patients diagnosed with locally advanced NSCLC, without any previous selection; and the concurrent CRT approach used, as opposed to other currently accepted treatment strategies for these patients, such as sequential CRT, definitive radiotherapy alone, or chemotherapy alone.

Our study has some limitations. It is a pilot exploratory study carried out at a single institution with a limited sample size, and our frailty assessments did not include any physical performance measure shown to have predictive ability (Guralnik et al, 1995). It is a nonrandomised study with a predetermined treatment strategy, so it was not designed to demonstrate whether patients would benefit from treatment regimens adapted to frailty profile. The ongoing ELDAPT clinical trial (NCT02284308) compares concurrent and sequential CRT in elderly patients with stage III NSCLC who have been assessed by CGA.

In conclusion, the present study demonstrates that CGA can identify elderly patients with inoperable, locally advanced NSCLC suitable for cCRT, with encouraging survival and toxicity outcomes. We observed a high capability of VES-13 for assessing prognosis and predicting toxicity, but these results need to be validated in a larger cohort. We hope this work will promote research in elderly patients who are candidates for multimodal treatment, correcting the existing misperceptions of poor outcomes based on outdated empirical treatment eligibility criteria. Large, multicentre studies in the field are a priority.

\section{ACKNOWLEDGEMENTS}

We thank Meggan Harris for her editorial assistance in the preparation of this paper. This study was partially supported by the Fund for Health Research (FIS, PI11/02011) and AGAUR (2014 SGR 0635). EN was supported by a Juan Rodés Scholarship from the Carlos III Institute of Health (JR13/0002).

\section{CONFLICT OF INTEREST}

The authors declare no conflict of interest.

\section{REFERENCES}

Antonio M, Saldaña J, Carmona-Bayonas A (2017) Geriatric assessment predicts survival and competing mortality in elderly patients with early colorectal cancer. can it help in adjuvant therapy decision-making? Oncologist 22: 1-10.

Atagi S, Kawahara M, Yokoyama A, Okamoto H, Yamamoto N, Ohe Y, Sawa T, Ishikura S, Shibata T, Fukuda H, Saijo N, Tamura T (2012) Thoracic radiotherapy with or without daily low-dose carboplatin in elderly patients with non-small-cell lung cancer: a randomised, controlled, phase 3 trial by the Japan Clinical Oncology Group (JCOG0301). Lancet Oncol 13: 671-678.

Aupérin A, Le Péchoux C, Rolland E, Curran WJ, Furuse K, Fournel P, Belderbos J, Clamon G, Ulutin HC, Paulus R, Yamanaka T, Bozonnat M-CC, Uitterhoeve A, Wang X, Stewart L, Arriagada R, Burdett S, Pignon J-PP (2010) Meta-analysis of concomitant versus sequential radiochemotherapy in locally advanced non-small-cell lung cancer. J Clin Oncol 28: 2181-2190.

Balducci L, Beghe C (2000a) The application of the principles of geriatrics to the management of the older person with cancer. Crit Rev Oncol Hematol 35: $147-154$.

Balducci L, Beghe C (2000b) The application of the principles of geriatrics to the management of the older person with cancer. Crit Rev Oncol Hematol 35: $147-154$. 
Bezjak A, Temin S, Franklin G, Giaccone G, Govindan R, Johnson ML, Rimner A, Schneider BJ, Strawn J, Azzoli CG (2015) Definitive and adjuvant radiotherapy in locally advanced non-small-cell lung cancer: American Society of Clinical Oncology Clinical Practice Guideline Endorsement of the American Society for Radiation Oncology EvidenceBased Clinical Practice Guideline. J Clin Oncol 33: 2100-2105.

Cardenal F, Nadal E, Jove M, Faivre-Finn C (2015) Concurrent systemic therapy with radiotherapy for the treatment of poor-risk patients with unresectable stage III non-small-cell lung cancer: a review of the literature. Ann Oncol 26: 278-288.

Corre R, Greillier L, Le Caer H, Audigier-Valette C, Baize N, Berard H, Falchero L, Monnet I, Dansin E, Vergnenegre A, Marcq M, Decroisette C, Auliac J-B, Bota S, Lamy R, Massuti B, Dujon C, Perol M, Daures J-P, Descourt R, Lena H, Plassot C, Chouaid C (2016) Use of a comprehensive geriatric assessment for the management of elderly patients with advanced non-small-cell lung cancer: the Phase III Randomized ESOGIA-GFPCGECP 08-02 Study. J Clin Oncol 34: 1476-1483.

D’Ath P, Katona P, Mullan E, Evans S, Katona C (1994) Screening, detection and management of depression in elderly primary care attenders. I: the acceptability and performance of the 15 item Geriatric Depression Scale (GDS15) and the development of short versions. Fam Pract 11: 260-266.

Davidoff AJ, Gardner JF, Seal B, Edelman MJ (2011) Population-based estimates of survival benefit associated with combined modality therapy in elderly patients with locally advanced non-small cell lung cancer. J Thorac Oncol 6: 934-941.

Dawe DE, Christiansen D, Swaminath A, Ellis PM, Rothney J, Rabbani R, Abou-Setta AM, Zarychanski R, Mahmud SM (2016) Chemoradiotherapy versus radiotherapy alone in elderly patients with stage III non-small cell lung cancer: a systematic review and meta-analysis. Lung Cancer 99: 180-185.

Decoster L, Van Puyvelde K, Mohile S, Wedding U, Basso U, Colloca G, Rostoft S, Overcash J, Wildiers H, Steer C, Kimmick G, Kanesvaran R, Luciani A, Terret C, Hurria A, Kenis C, Audisio R, Extermann M (2015) Screening tools for multidimensional health problems warranting a geriatric assessment in older cancer patients: an update on SIOG recommendations $\dagger$. Ann Oncol 26: 288-300.

Eberhardt WEE, De Ruysscher D, Weder W, Le Péchoux C, De Leyn P, Hoffmann H (2015) 2nd ESMO Consensus Conference in Lung Cancer: locally advanced stage III non-small-cell lung cancer. Ann Oncol 26: 1573-1588.

Extermann M, Aapro M, Bernabei R, Cohen HJ, Droz J-P, Lichtman S, Mor V, Monfardini S, Repetto L, Sørbye L, Topinkova E (2005) Use of comprehensive geriatric assessment in older cancer patients: recommendations from the task force on CGA of the International Society of Geriatric Oncology (SIOG). Crit Rev Oncol Hematol 55: 241-252.

Extermann M, Hurria A (2007) Comprehensive geriatric assessment for older patients with cancer. J Clin Oncol 25: 1824-1831.

Firat S, Pleister A, Byhardt RW, Gore E (2006) Age is independent of comorbidity influencing patient selection for combined modality therapy for treatment of stage III nonsmall cell lung cancer (NSCLC). Am J Clin Oncol 29: 252-257.

Furuse K, Kubota K, Kawahara M, Kodama N, Ogawara M, Akira M, Nakajima S, Takada M, Kusunoki Y, Negoro S (1995) Phase II study of concurrent radiotherapy and chemotherapy for unresectable stage III nonsmall-cell lung cancer. Southern Osaka Lung Cancer Study Group. J Clin Oncol 13: 869-875.

Gajra A, Loh KP, Hurria A, Muss H, Maggiore R, Dale W, Klepin HD, Magnuson A, Lichtman SM, Williams GR, Shahrokhni A, Mohile SG (2016) Comprehensive geriatric assessment-guided therapy does improve outcomes of older patients with advanced lung cancer. J Clin Oncol 34: 4047-4048

Guralnik JM, Ferrucci L, Simonsick EM, Salive ME, Wallace RB (1995) Lowerextremity function in persons over the age of 70 years as a predictor of subsequent disability. $\mathrm{N}$ Engl J Med 332: 556-561.

Hamaker ME, Wildes TM, Rostoft S (2017) Time to stop saying geriatric assessment is too time consuming. J Clin Oncol 35: 2871-2874.

Handforth C, Clegg A, Young C, Simpkins S, Seymour MT, Selby PJ, Young J (2014) The prevalence and outcomes of frailty in older cancer patients: a systematic review. Ann Oncol 26: 1091-1101.

Hung A, Mullins CD (2013) Relative effectiveness and safety of chemotherapy in elderly and nonelderly patients with stage III colon cancer: a systematic review. Oncologist 18: 54-63.

Jolly TA, Deal AM, Nyrop KA, Williams GR, Pergolotti M, Wood WA, Alston SM, Gordon B-BE, Dixon SA, Moore SG, Taylor WC, Messino M, Muss HB (2015)
Geriatric assessment-identified deficits in older cancer patients with normal performance status. Oncologist 20: 379-385.

Kalsi T, Babic-Illman G, Ross PJ, Maisey NR, Hughes S, Fields P, Martin FC, Wang Y, Harari D (2015) The impact of comprehensive geriatric assessment interventions on tolerance to chemotherapy in older people. $\mathrm{Br}$ J Cancer 112: 1435-1444.

Karampeazis A, Vamvakas L, Kotsakis A, Christophyllakis C, Kentepozidis N, Chandrinos V, Agelidou A, Polyzos A, Tsiafaki X, Hatzidaki D, Georgoulias V (2017) Docetaxel plus gemcitabine versus gemcitabine in elderly patients with advanced non-small cell lung cancer and use of a geriatric assessment: lessons from a prematurely closed Hellenic Oncology Research Group randomized phase III study. J Geriatr Oncol 8: 23-30.

Kong F-M, Ritter T, Quint DJ, Senan S, Gaspar LE, Komaki RU, Hurkmans CW, Timmerman R, Bezjak A, Bradley JD, Movsas B, Marsh L, Okunieff P, Choy H, Curran WJ (2011) Consideration of dose limits for organs at risk of thoracic radiotherapy: atlas for lung, proximal bronchial tree, esophagus, spinal cord, ribs, and brachial plexus. Int J Radiat Oncol 81: 1442-1457.

Lawton MP, Brody EM (1969) Assessment of older people: self-maintaining and instrumental activities of daily living. Gerontologist 9: 179-186.

Linn BS, Linn MW, Gurel L (1968) Cumulative illness rating scale. J Am Geriatr Soc 16: 622-626.

Locher C, Pourel N, Marin B, Vergnenègre A, et le GFPC (2011) A phase II study of weekly cisplatine plus oral vinorelbine with concomittant radiotherapy in non-dependent elderly patients with localized inoperable non small cell lung carcinoma (Essai GFPC 08-06, Raccosa]. Rev Mal Respir 28: 58-65.

Luciani A, Biganzoli L, Colloca G, Falci C, Castagneto B, Floriani I, Battisti N, Dottorini L, Ferrari D, Fiduccia P, Zafarana E, Del Monte F, Galli F, Monfardini S, Foa P (2015) Estimating the risk of chemotherapy toxicity in older patients with cancer: the role of the Vulnerable Elders Survey-13 (VES-13). J Geriatr Oncol 6: 272-279.

Mahoney FI, Barthel DW (1965) Functional evaluation: the Barthel index. Md State Med J 14: 61-65.

Maione P, Perrone F, Gallo C, Manzione L, Piantedosi F, Barbera S, Cigolari S, Rosetti F, Piazza E, Robbiati SF, Bertetto O, Novello S, Migliorino MR, Favaretto A, Spatafora M, Ferraù F, Frontini L, Bearz A, Repetto L, Gridelli C, Barletta E, Barzelloni ML, Iaffaioli RV, De Maio E, Di Maio M, De Feo G, Sigoriello G, Chiodini P, Cioffi A, Guardasole V, Angelini V, Rossi A, Bilancia D, Germano D, Lamberti A, Pontillo V, Brancaccio L, Renda F, Romano F, Esani G, Gambaro A, Vinante O, Azzarello G, Clerici M, Bollina R, Belloni P, Sannicolò M, Ciuffreda L, Parello G, Cabiddu M, Sacco C, Sibau A, Porcile G, Castiglione F, Ostellino O, Monfardini S, Stefani M, Scagliotti G, Selvaggi G, De Marinis F, Martelli O, Gasparini G, Morabito A, Gattuso D, Colucci G, Galetta D, Giotta F, Gebbia V, Borsellino N, Testa A, Malaponte E, Capuano Ma, Angiolillo M, Sollitto F, Tirelli U, Spazzapan S, Adamo V, Altavilla G, Scimone A, Hopps MR, Tartamella F, Ianniello G Pietro, Tinessa V, Failla G, Bordonaro R, Gebbia N, Valerio MR, D’Aprile M, Veltri E, Tonato M, Darwish S, Romito S, Carrozza F, Barni S, Ardizzoia A, Corradini GM, Pavia G, Belli M, Colantuoni G, Galligioni E, Caffo O, Labianca R, Quadri A, Cortesi E, D’Auria G, Fava S, Calcagno A, Luporini G, Locatelli MC, Di Costanzo F, Gasperoni S, Isa L, Candido P, Gaion F, Palazzolo G, Nettis G, Annamaria A, Rinaldi M, Lopez M, Felletti R, Di Negro GB, Rossi N, Calandriello A, Maiorino L, Mattioli R, Celano A, Schiavon S, Illiano A, Raucci CA, Caruso M, Foa P, Tonini G, Curcio C, Cazzaniga M (2005) Pretreatment quality of life and functional status assessment significantly predict survival of elderly patients with advanced non-small-cell lung cancer receiving chemotherapy: a prognostic analysis of the multicenter Italian lung cancer in the elderly s. J Clin Oncol 23: $6865-6872$.

Pallis AG, Gridelli C, Wedding U, Faivre-Finn C, Veronesi G, Jaklitsch M, Luciani A, O’Brien M (2014) Management of elderly patients with NSCLC; updated expert's opinion paper: EORTC Elderly Task Force, Lung Cancer Group and International Society for Geriatric Oncology. Ann Oncol 25: 1270-1283.

Pang HH, Wang X, Stinchcombe TE, Wong ML, Cheng P, Ganti AK, Sargent DJ, Zhang Y, Hu C, Mandrekar SJ, Redman MW, Manola JB, Schilsky RL, Cohen HJ, Bradley JD, Adjei AA, Gandara D, Ramalingam SS, Vokes EE (2016) Enrollment trends and disparity among patients with lung cancer in National Clinical Trials, 1990 to 2012. J Clin Oncol 34: 3992-3999.

Pfeiffer E (1975) A short portable mental status questionnaire for the assessment of organic brain deficit in elderly patients. J Am Geriatr Soc 23: 433-441. 
Ramnath N, Dilling TJ, Harris LJ, Kim AW, Michaud GC, Balekian AA, Diekemper R, Detterbeck FC, Arenberg DA (2013) Treatment of stage III non-small cell lung cancer: diagnosis and management of lung cancer, 3rd ed: American College of Chest Physicians evidence-based clinical practice guidelines. Chest 143: e314S-e3140.

Rocha Lima CMS, Herndon JE, Kosty M, Clamon G, Green MR (2002) Therapy choices among older patients with lung carcinoma: an evaluation of two trials of the Cancer and Leukemia Group B. Cancer 94: 181-187.

O’Rourke N, Roqué I Figuls M, Farré Bernadó N, Macbeth F (2010) Concurrent chemoradiotherapy in non-small cell lung cancer. Cochrane Database Syst Rev (Review 6): CD002140.

De Ruysscher D, Faivre-Finn C, Nestle U, Hurkmans CW, Le Pechoux C, Price A, Senan S (2010) European Organisation for Research and Treatment of Cancer recommendations for planning and delivery of high-dose, highprecision radiotherapy for lung cancer. J Clin Oncol 28: 5301-5310.

Saliba D, Elliott M, Rubenstein LZ, Solomon DH, Young RT, Kamberg CJ, Roth C, MacLean CH, Shekelle PG, Sloss EM, Wenger NS (2001) The vulnerable elders survey: a tool for identifying vulnerable older people in the community. J Am Geriatr Soc 49: 1691-1699.

Santana-Davila R, Devisetty K, Szabo A, Sparapani R, Arce-Lara C, Gore EM, Moran A, Williams CD, Kelley MJ, Whittle J (2015) Cisplatin and etoposide versus carboplatin and paclitaxel with concurrent radiotherapy for stage III non-small-cell lung cancer: an analysis of Veterans Health Administration data. J Clin Oncol 33: 567-574.

Schild SE, Mandrekar SJ, Jatoi A, McGinnis WL, Stella PJ, Deming RL, Jett JR, Garces YI, Allen KL, Adjei AA (2007) The value of combined-modality therapy in elderly patients with stage III nonsmall cell lung cancer. Cancer 110: 363-368.

Schulkes KJG, Hamaker ME, van den Bos F, van Elden LJR (2016) Relevance of a geriatric assessment for elderly patients with lung cancer-a systematic review. Clin Lung Cancer 17: 341-349.e3.

Solomon D, Sue Brown A, Brummel-Smith K, Burgess L, D'Agostino RB, Goldschmidt JW, Halter JB, Hazzard WR, Jahnigen DW, Phelps C, Raskind M, Schrier RW, Sox HC, Williams SV, Wykle M (2003) Best Paper of the 1980s: â€National Institutes of Health Consensus Development Conference Statement: Geriatric Assessment Methods for Clinical Decision-Making. J Am Geriatr Soc 51: 1490-1494.
Steuer CE, Behera M, Ernani V, Higgins KA, Saba NF, Shin DM, Pakkala S, Pillai RN, Owonikoko TK, Curran WJ, Belani CP, Khuri FR, Ramalingam SS (2016) Comparison of concurrent use of thoracic radiation with either carboplatin-paclitaxel or cisplatin-etoposide for patients with stage iii non-small-cell lung cancer: a systematic review. JAMA Oncol 3(8): $1120-1129$.

Stinchcombe TE, Zhang Y, Vokes EE, Schiller JH, Bradley JD, Kelly K, Curran WJ, Schild SE, Movsas B, Clamon G, Govindan R, Blumenschein GR, Socinski MA, Ready NE, Akerley WL, Cohen HJ, Pang HH, Wang X (2017) Pooled analysis of individual patient data on concurrent chemoradiotherapy for stage III non-small-cell lung cancer in elderly patients compared with younger patients who participated in US National Cancer Institute Cooperative Group Studies. J Clin Oncol 35(25): 2885-2892.

Walters S, Maringe C, Coleman MP, Peake MD, Butler J, Young N, Bergström S, Hanna L, Jakobsen E, Kölbeck K, Sundstrøm S, Engholm G, Gavin A, Gjerstorff ML, Hatcher J, Johannesen TB, Linklater KM, McGahan CE, Steward J, Tracey E, Turner D, Richards Ma, Rachet B (2013) Lung cancer survival and stage at diagnosis in Australia, Canada, Denmark, Norway, Sweden and the UK: a population-based study, 2004-2007. Thorax 68: 551-564.

Werner-Wasik M, Scott C, Cox JD, Sause WT, Byhardt RW, Asbell S, Russell A, Komaki R, Lee JS (2000) Recursive partitioning analysis of 1999 radiation therapy oncology group (RTOG) patients with locally-advanced non-small-cell lung cancer (LA-NSCLC): Identification of five groups with different survival. Int J Radiat Oncol 48: 1475-1482.

Wingo Pa, Cardinez CJ, Landis SH, Greenlee RT, Ries LaG, Anderson RN, Thun MJ (2003) Long-term trends in cancer mortality in the United States, 1930-1998. Cancer 97: 3133-3275.

This work is published under the standard license to publish agreement. After 12 months the work will become freely available and the license terms will switch to a Creative Commons AttributionNonCommercial-Share Alike 4.0 Unported License.

Supplementary Information accompanies this paper on British Journal of Cancer website (http://www.nature.com/bjc) 